\title{
Gas Phase Carbon Dioxide as an Optimum Substrate for Isocitrate Dehydrogenase Reaction
}

\author{
Shunxiang Xia ${ }^{1,2}$, Enjelia Veony $^{2}$ \\ ${ }^{1}$ Department of Bioproducts and Biosystems Engineering, University of Minnesota, Saint Paul, MN55108, USA \\ ${ }^{2}$ Department of Petroleum Engineering, University of Houston, Houston, TX 77023, USA
}

\begin{abstract}
As biocatalytic carbon capture has attracted wide attraction due to its high energy efficiency, the preference of carbon species of the reaction is concerned. The self-evolution between carbon species makes the determination of preference a changeling issue. In this study, by comparing the isocitrate dehydrogenase reaction rate profiles with pre-equilibrated and unequilibrated HCO3--CO2 solutions, gas phase carbon dioxide was believed as the optimum substrate, as it can provide higher reaction rate. During the carbon capture process, the partial pressure of the carbon dioxide affected both the reaction equilibrium and kinetics, while the interfacial area can only determine the reaction rate.
\end{abstract}

\section{Introduction}

As the most significant anthropogenic greenhouse gas, carbon dioxide emitted as an industrial pollution waste can be probably most effectively handled by the Carbon Capture and Storage (CCS) strategy. The current chemical based CCS is realized through selective absorption of $\mathrm{CO}_{2}$ from flue gas using amino acid salt solvent and subsequent desorption to gain high purity $\mathrm{CO}_{2}$. The most obvious disadvantage of chemical CCS is its poor energy efficiency. As the regeneration of absorbent results in a huge temperature shifting $\left(\sim 150^{\circ} \mathrm{C}\right)$, most energy was wasted in heating the water portion of absorbent $(\sim 70 \mathrm{w} / \mathrm{w} \%)$. Recent Concerns have been raised about seeking alternative carbon capture approach. Compared with chemical absorbent reactions, biological absorption can be proceeding at ambient conditions with high reaction specificity and unparalleled high energy efficiency [1]. Among these carbon fixations, ICDH reaction has attracted wide attention due to its reversibility and comparable high specific activity [2]. By shifting the system $\mathrm{Ph}$ instead of temperature, the direction of reaction can be manipulated, realizing the carbon capture and release strategy [3].

One concern about biocatalytic carbon dioxide capture is the utilization efficiency of carbon species. The Km values of carbon dioxide for enzyme reaction is around $100 \mu \mathrm{M}$ to $1 \mathrm{mM}$, in accord with the low solubility of carbon dioxide $(350 \mu \mathrm{M}$ with $1 \mathrm{v} / \mathrm{v} \%$ carbon dioxide in atmosphere pressure). According to Henry's law, the solubility of carbon dioxide is limited by the partial pressure of carbon dioxide. Moreover, the carbon species exhibits self-evolution in aqueous solution and four forms of carbon dioxide $\left(\mathrm{CO}_{2}, \mathrm{H}_{2} \mathrm{CO}_{3}, \mathrm{HCO}_{3}{ }^{-}\right.$and $\left.\mathrm{CO}_{3}{ }^{2-}\right)$ exist in equilibrium which is strongly affected by the system $\mathrm{pH}$. As the conversion rates between the carbon species are much faster than the enzyme reaction rates, the substrate selectivity of carbon species is rarely mentioned. Instead, $\mathrm{CO}_{2}$ (tot) is used to represent the overall characteristics of carbon species. The structure of active site of enzymes may bring some clue about its selectivity. According to the enzyme structure, $\mathrm{HCO}_{3}{ }^{-}$was proven to the primary substrate for propiony1-CoA carboxylase [4], while dissolved gas phase carbon dioxide was believed as the dominated substrate for most carboxylases originated from the yeast [5].

The neglection may cause high uncertainty during largescale carbon capture, when the carboxylation reaction is conducted with high intensity. The selectivity of carbon species would significantly affect the reaction rate since carbon equilibrium may not be completed before the contact of enzyme and carbon species. In this study, the selectivity of ICDH on carbon species was studied for efficient carbon capture.

\section{Material and methods}

\subsection{Material}

Ketoglutarate, NADPH, 2-(N morpholino) ethanesulfonic acid (Mes), Magnesium chloride, Carbon anhydrase (CA) and isocitrate dehydrogenase (ICDH) from porcine heart 
(EC 1.1.1.42) were purchased form Sigma Chemical Co. (St. Louis, USA).

\subsection{Determination of selectivity of carbon substrate}

The selectivity of carbon substrate was revealed by comparison of the initial carboxylation reaction rate of ICDH with pre-equilibrated and un-equilibrated $\mathrm{HCO}_{3}^{-}-$ $\mathrm{CO}_{2}$ solutions. The reactions were conducted with the standard concentration of substrate except NADPH (200 $\mu \mathrm{M}$ ) for carboxylation with both $\mathrm{pH} 6.5$ and $\mathrm{pH} 7.5$ MES buffer which was pre-treated with pure nitrogen to remove the potential dissolved carbon dioxide. For preequilibrated $\mathrm{HCO}_{3}^{-}--\mathrm{CO}_{2}$ group, before adding an enzyme, the solution was bubbled with gas phase carbon dioxide through the plastic tube settled in the bottom of the cuvette about 1-2 seconds and waited for the equilibrium of carbon species in 5 mins. After adding the enzyme, the decline curve of concentration of NADPH was recorded by spectrophotometer. For un-equilibrated $\mathrm{HCO}_{3}{ }^{-}-\mathrm{CO}_{2}$ group, the same process was conducted except that the enzyme was added immediately after bubbling carbon dioxide.

To further analyze the enzyme reaction rate with different carbon species, carbon anhydrase was introduced in the un-equilibrated group to accelerate the conversion of dissolved gas phase carbon dioxide to HCO3-. $0.1 \mathrm{mg}$ of CA was added and mixed with the solution quickly with a pipette $15 \mathrm{~s}$ later than the initiation of the reaction. The decline curve of the concentration of NADPH was recorded and compared with that of the previous group without CA to reveal the difference.

\subsection{Carbon dioxide capture with bubbling gas mixture}

The gas capture experiment was conducted by continuously bubbling mixing gas into absorption solvent (Figure 1). Carbon dioxide and nitrogen released from high-pressure cylinders and the total flow rate was fixed at $30 \mathrm{ml} / \mathrm{min}$ by a gas gauge. The gas was mixed and bubbled through a plastic tube at bottom of a $20-\mathrm{ml}$ gas bottle filled with adsorption solvent. The concentrations of ketoglutarate, NADPH and $\mathrm{MgCl}_{2}$ in adsorption solution were fixed at 5,5 and $40 \mathrm{mM}$ in $100 \mathrm{mM} \mathrm{pH} 7$ MES buffer and the solvent was bubble nitrogen to remove the dissolved carbon dioxide before added enzyme. $1 \mathrm{U}$ of ICDH was added into the absorption solvent to initiate the reaction, and for a prepaid time, the concentration of NADPH was monitored at A340 with the spectrophotometer. The concentration difference of NAPDH between experiment and control samples (not add enzyme) were compared to calculate the amount of carbon captured.

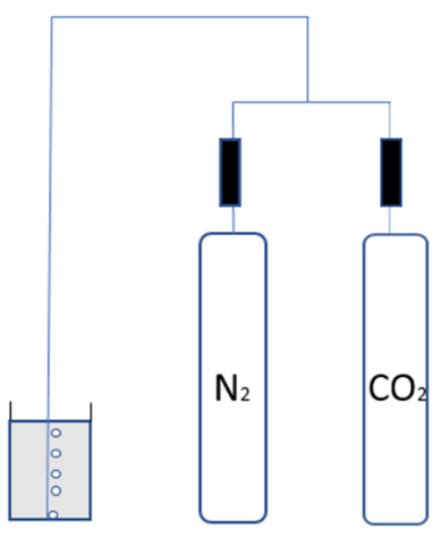

Fig. 1. Scheme of carbon dioxide capture with bubbling gas mixture.

\subsection{Carbon dioxide capture with surface covered with mixture gas}

The carbon dioxide capture experiment was also conducted with the following design (Figure 2). The concentration of absorption solvent was the same as bubbling gas test but the carbon dioxide was supplied through interfacial mass transfer. The volume of solvent was $20 \mathrm{~mL}$ in a glass bottle, and the interfacial area was controlled with plastic foam. A 100-ml beaker covered the glass bottle and its chamber filled with gas mixture. After adding enzyme into the absorption solvent, the glass bottle was quickly moved to the chamber of the beaker. Gas mixture flow rate was kept at $30 \mathrm{ml} / \mathrm{min}$ to maintain the partial gas pressure of carbon dioxide, and the solvent was stirred at $200 \mathrm{rpm}$. For a prepaid time, $200 \mu \mathrm{l}$ of the solvent was removed with pipette quickly, and the concentration of NADPH was monitored at A340 with the spectrophotometer.

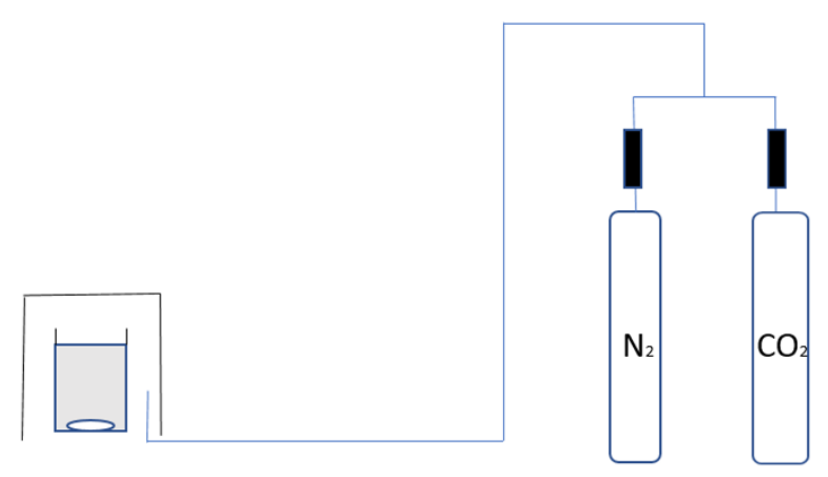

Fig. 2. Scheme of carbon dioxide capture with surface covered with mixture gas.

\section{Results and discussion}

\subsection{Optimum substrate for carboxylation reaction} When the $\mathrm{pH}$ of the solution is between 5 to 7 , three forms of carbon dioxide $\left(\mathrm{CO}_{2}, \mathrm{H}_{2} \mathrm{CO}_{3}\right.$ and $\left.\mathrm{HCO}_{3}{ }^{-}\right)$exist in equilibrium according to the following reaction: 


$$
\mathrm{CO}^{2}+\mathrm{H}_{2} \mathrm{O} \leftrightarrow \mathrm{H}_{2} \mathrm{CO}_{3} \leftrightarrow \mathrm{H}^{+}+\mathrm{HCO}_{3}^{-}
$$

While the second ionization reaction is almost instantaneous, the rate of first hydration reaction is comparatively low. The ionization constant could be expressed as following:

$$
K_{1}=\frac{\left[\mathrm{HCO}_{3}-\right][\mathrm{H+}]}{\left[\mathrm{H}_{2} \mathrm{CO}_{3}\right]}
$$

At room temperature, the value of $\mathrm{K}_{1}$ is about 3.0 $\mathrm{X} 10^{-4} \mathrm{M}$, so the concentration of $\mathrm{H}_{2} \mathrm{CO}_{3}$ can be neglected at our $\mathrm{pH}$ range and the equation (1) was simplified as

$$
\mathrm{CO}_{2} \leftrightarrow \mathrm{HCO}_{3}^{-}
$$

And the concentration of dissolved carbon dioxide was described as

$$
\frac{d\left[\mathrm{CO}_{2}\right]}{d t}=k\left[\mathrm{HCO}_{3}^{-}\right]-k^{\prime}\left[\mathrm{CO}_{2}\right]
$$

Where $\mathrm{k}=0.015 \mathrm{sec}^{-1}$ and $\mathrm{k}^{\prime}=0.015 \mathrm{sec}^{-1}$ at $\mathrm{pH} 6.5$, and $\mathrm{k}=0.002 \mathrm{sec}^{-1}$ and $\mathrm{k}^{\prime}=0.015 \mathrm{sec}^{-1}$ at $\mathrm{pH} 7.5$.

The value of $\mathrm{HCO}_{3}{ }^{-} / \mathrm{CO}_{2}$ ratio is calculated to be about 1 at $\mathrm{pH} 6.5$ and 8 at $\mathrm{pH} 7.5$. Considering the reaction (4) is a first order reaction, the integrated rate equation for the approach to equilibrium from one side is

$$
\left(k+k^{\prime}\right) t=2.3 \log \left[\left(\frac{C e}{C e-C t}\right]\right.
$$

Where $\mathrm{C}_{e}$ is the concentration of product under equilibrium and $\mathrm{C}_{\mathrm{t}}$ is the concentration of product at time t.

Based on the equation (5), the times required to reach $50 \%$ of equilibrium are 23 and 40 seconds under $\mathrm{pH} 6.5$ and 7.5 respectively and times to reach $90 \%$ of equilibrium are 77 and 138 seconds.

The selectivity of carboxylation reaction with carbon species was revealed through the comparison of carboxylation reaction rate profiles with pre-equilibrated and un-equilibrated $\mathrm{HCO}_{3}-\mathrm{CO}_{2}$ solutions (Figure 3). Although the total concentration of carbon species in these two kinds of solutions was the same, the ratio of $\mathrm{CO}_{2}$ and $\mathrm{HCO}_{3}{ }^{-}$decreased during the experiment in unequilibrated solution but appeared constant in preequilibrated due to the carbon self-evolution. To get unequivocal kinetics, the reaction condition need fulfill three criterions : i) the window of observation is only several mins after the initiation of the reaction as the carbon evolution is not completed; ii) the concentration of carbon species must be the limited substrate to show the sensitive of reaction on the concentration of gas phase of $\mathrm{CO}_{2}$; iii) the rate of carbon species consumption must all be small to neglect the change of total carbon concentration.

Carboxylation reaction progress was compared in Figure 3 , taking the concentration of NADPH as an indicator. At both $\mathrm{pH} 6.5$ and 7.5 , the pre-equilibrated solution provided a constant reaction rate for complete two minutes of the reaction time, $35 \mu \mathrm{M}$ and $64 \mu \mathrm{M}$ of carbon was fixed respectively. In contrast to preequilibrated solution, a decline of the carboxylation rate was observed for un-equilibrated groups at two $\mathrm{pHs}$. At $\mathrm{pH} 7.5$, the reaction rate in the first min was $32 \mu \mathrm{M} / \mathrm{min}$, much higher than that of pre-equilibrated (17.5 $\mu \mathrm{M} / \mathrm{min})$. In the second $\mathrm{min}$, the reaction rate decreased to 16 $\mathrm{uM} / \mathrm{min}$, close to the equilibrium group. The difference of kinetics between pre-equilibrated and non-equilibrated was more obvious at $\mathrm{pH}$ 6.5: the reaction rate was 60 $\mu \mathrm{M} / \mathrm{min}$ for the non-equilibrated solution in the first 30 seconds, almost twice of the rate for equilibrium group. However, the reaction rate decreased quickly and almost equalled the equilibrium group's rates after one minute.
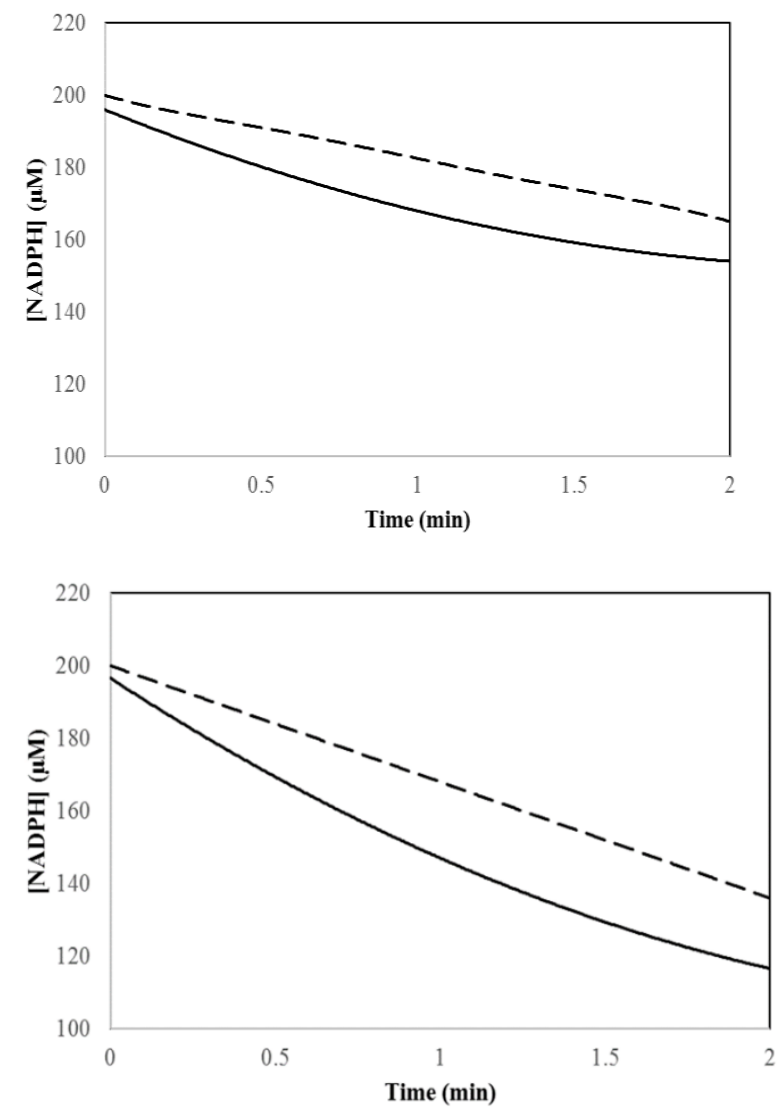

Fig. 3. The progress of carboxylation reaction catalyzed by ICDH with different carbon resource under $\mathrm{pH} 7.5$ (left) and $\mathrm{pH}$ 6.5(right) (Dash line: pre-equilibrated $\mathrm{HCO} 3--\mathrm{CO} 2$ solution; Solid line: bubbling the $\mathrm{CO} 2$ into buffer solution without equilibrium).

These results indicated that dissolved carbon dioxide was the primary substrate for the carboxylation reaction catalyzed by ICDH. A higher reaction rate was obtained

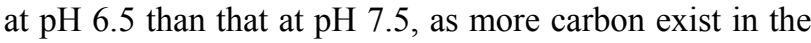
form of dissolved gas phase to conduct the carboxylation reactions at $\mathrm{pH}$ 6.5. Moreover, for the un-equilibrium group, the reaction rate decrease was in accord with the conversion of dissolved gas carbon dioxide to $\mathrm{HCO}_{3}{ }^{-}$. At $\mathrm{pH} 6.5$, the highest reaction rate was detected in the beginning when most of conversion did not happen. With time, gaseous $\mathrm{CO}_{2}$ began to evolve to $\mathrm{HCO}_{3}^{-}$, lowering the concentration of gaseous $\mathrm{CO}_{2}$ and resulting in the decrease of the reaction rate. After two mins, the carbon species equilibrated and the reaction rate became constant and equaled that of pre-equilibrium group. At $\mathrm{pH} 7.5$, the time required for carbon species to achieve equilibrium was longer than that at $\mathrm{pH} 6.5$, representing a longer gap of reaction rate between the two groups. 
In order to further confirm the assumption, carbon anhydrase (CA) was introduced to change the evolution profile of carbon species in solution. Acting as a catalyst, CA could make the reaction (3) reach the equilibrium almost instantaneously [6]. The effects of CA on the carboxylation reaction were described in Figure 4.

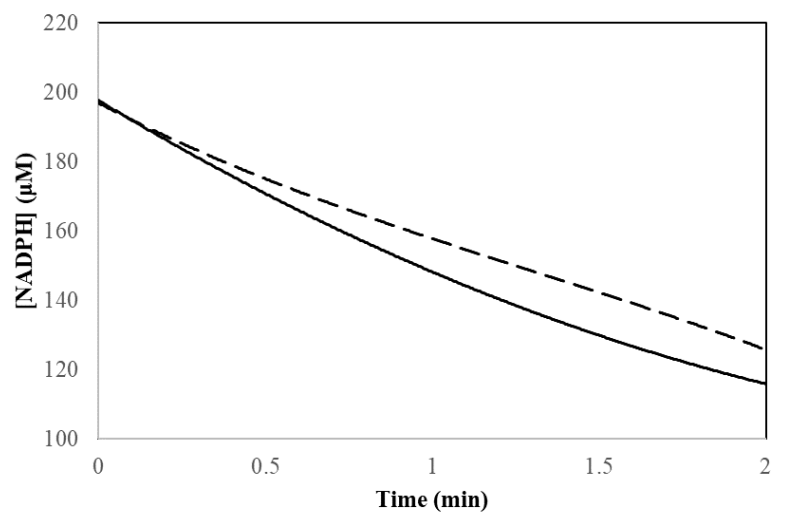

Fig. 4. The progress of carboxylation reaction catalyzed by ICDH under pH 6.5 (Solid line: no CA; Dash line: adding CA at 15 second).

In Figure 4, bubbled carbon dioxide was supplied as substrate and CA was added into the system at 15 second after the reaction start. After adding $\mathrm{CA}$, the reaction rate decreased instantaneously with the conversion of gas phase carbon dioxide to $\mathrm{HCO} 3$ - and the reaction rate became constant due to the equilibration of carbon species after another 30 seconds. Without CA, the equilibrium was achieved at 1.5 mins, much later than the CA group.

The preferred utilization of gas phase carbon dioxide was originated with the mechanism of the enzyme reaction. By labeling the single tritium atom in 2-oxo[3-3H] glutarate, Dalziel found that during the first step of carboxylation, enzyme bound and enolated the 2oxoglutarate to form carbanion intermediate. In this step, $\mathrm{Mg}^{2+}$ and NADPH were necessary to maintain the structure of intermediate. In the following step, the carbanion intermediate was further converted to isocitrate by the selectively electrophilic attack of the gas phase $\mathrm{CO}_{2}$ instead of other carbon species [7].

This preference could provide guidance for improving the carbon fixation. First of all, locating the enzyme just close to the interface between flue gas and reaction solution can be helpful since more gas phase approaches the enzyme before its evolution. Many membranes and foam bioreactors providing high mass transfer of carbon dioxide between gas and solution phase are suitable for this propose [8]. However, the high mass flux of carbon dioxide may bring severe shear stress, which negative effects on the enzyme stability. Also, this quick contact of the enzyme with flue gas requires stricter pretreatment of the toxic compounds of flue gas since there is less solution barrier between the gas and enzyme. Secondly, the carbon capture would benefit from addition of CA to accelerate the reversible conversion of dissolved $\mathrm{CO}_{2}$ and $\mathrm{HCO}_{3}{ }^{-}$. When the carboxylation reaction rate is much higher than the rate of conversion $\mathrm{HCO}_{3}{ }^{-}$to $\mathrm{CO}_{2}$, the local dissolved $\mathrm{CO}_{2}$ will deplete quickly, and therefore the conversion rate of carbon species limits the apparent carboxylation reactions. With $\mathrm{CA}$, the local dissolved carbon dioxide can be replenished from $\mathrm{HCO}_{3}^{-}$ immediately to supply the carboxylation reactions. In the end, since the selectivity of carbon species for the enzyme is related to the enzyme structure, modification of amino acid of the enzyme through genetic method may change this selectivity of carbon species to improve overall carboxylation.

\subsection{Gas phase carbon dioxide capture}

When gas phase carbon dioxide is utilized as the substrate, the gas phase carbon dioxide needs to be transferred from gas phase to liquid phase forming dissolved carbon dioxide, then the dissolved $\mathrm{CO}_{2}$ and its hydration product can diffuse to the location of enzyme molecules. The carbon dioxide captures with different carbon dioxide concentrations were conducted and the rates were depicted in Figure 5.

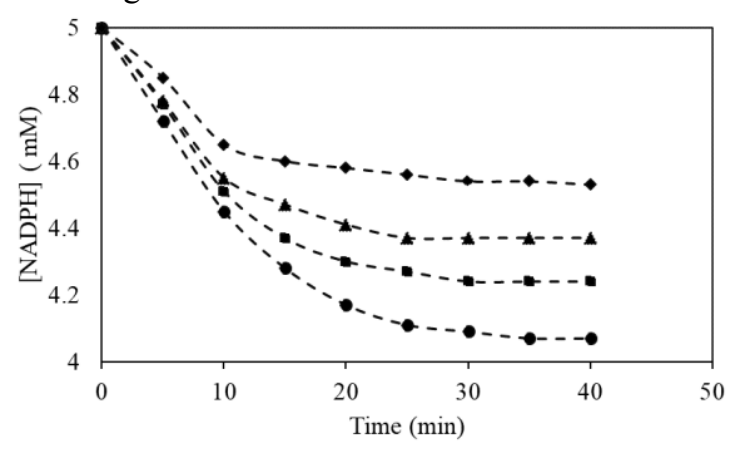

Fig. 5. Carbon dioxide capture rate with different concentration of carbon dioxide

$$
\text { (A : } 15 \% ;>30 \% ; \square: 60 \% ; \bigcirc: 100 \% \text { ). }
$$

After 40 mins, the reaction of all the samples reached equilibrium, representing a flat kinetic curve. The solution absorbed different amount of carbon dioxide with various carbon dioxide concentration. For pure carbon dioxide, $0.93 \mathrm{mM}$ carbon was captured with 5 $\mathrm{mM}$ cofactor supplied, while the amount of carbon captured decreased sharply with lower carbon dioxide concentration. With $15 \%$ carbon dioxide, only $0.47 \mathrm{mM}$ carbon was captured. According to Henry's law, low concentration of carbon dioxide brought low solubility of carbon dioxide, resulted in an unfavorability for the carbon capture equilibrium [9].

In this figure, a linear and sharp decline curve was observed at the beginning of the reaction with $30 \%$ $100 \%$ carbon dioxide. In this period, the mass transfer of carbon dioxide from gas to liquid did not limit the overall carbon capture rate. With $15 \%$ carbon dioxide, however, the mass transfer limitation of carbon dioxide became obvious, as a smaller slope of the decline curve was observed in the initial 10 mins. Theoretically, the mass transfer of carbon dioxide is related to transfer area $\left(A_{d}\right)$, equilibrium point concentration $\left(\mathrm{C}_{\mathrm{e}}\right)$, and mass transfer constant $\left(\mathrm{K}_{\mathrm{L}}\right)$ (equation 6). As the carbon dioxide concentration affected the $\mathrm{Ce}$, a lower mass transfer corresponded with lower carbon dioxide concentration.

$$
v_{d}(d C / d t)=k_{L} A_{d}\left(C_{e}-C\right)
$$


To further reveal the effect of carbon dioxide transfer issue, the carbon capture curve with carbon dioxide covered the surface of solvent was shown in Figure 6.

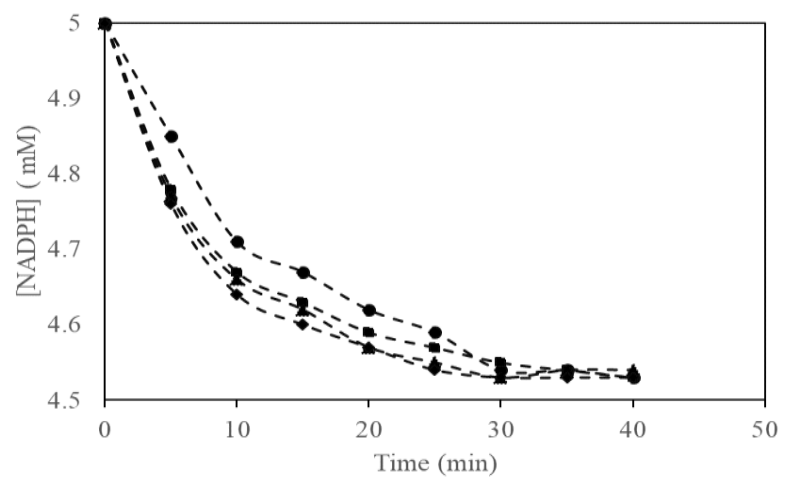

Fig. 6. Carbon dioxide capture rate with different surface area covered with carbon dioxide

$\left.2 \mathrm{~cm}^{2} ; \mathbf{\Delta} 1.5 \mathrm{~cm}^{2} ; \mathrm{cm}^{2} ; 0.5 \mathrm{~cm}^{2}\right)$.

As the final equilibrium point of carbon capture was reached with $15 \%$ carbon dioxide, $0.47 \mathrm{mM}$ carbon was captured for all the samples, in accord with the results of bubbling gas method. The mass transfer rates of carbon dioxide, controlled by the interfacial area, determined the initial rates of carbon capture. Based on the results, samples that had the interfacial area between $1 \mathrm{~cm}^{2}$ and 2 $\mathrm{cm}^{2}$ possessed a similar carbon capture rate, but a lower initial rate was observed for the sample with $0.5 \mathrm{~cm}^{2}$ interfacial area, revealing a mass transfer limited phenomenon [10]. Only $0.7 \mathrm{mM}$ carbon dioxide was theoretically transferred with $0.5 \mathrm{~cm}^{2}$ interfacial area in 5 mins, as the value of $\mathrm{K}_{\mathrm{L}}$ and $\mathrm{C}_{\mathrm{e}}$ are $0.0252 \mathrm{~cm} / \mathrm{s}$ and 5.25 $\mathrm{mM}$ respectively. Regarding the $\mathrm{Km}$ value of $\mathrm{ICDH}(\sim 1$ $\mathrm{mM})$, the concentration of carbon dioxide is insufficient to realize the maximum reaction rate [11]. With more interfacial area, more dissolved carbon dioxide was accumulated in the solvent and accelerated the reaction rate.

\section{Conclusion}

Gas phase carbon dioxide is believed to be the primary substrate for ICDH reaction because it can provide higher reaction rate then bicarbonate. The preference of carbon species can bring clue about the enzyme reaction mechanism. In gas capture experiment, both partial pressure of carbon dioxide and interfacial area affected the overall carbon capture rate and external mass transfer can be the limiting factor to the high carbon capture rate.

\section{References}

1. Cheng H, Du B, Pi C, Jang M, Lin H and Lee T 2011 Comparative study of lipid extraction from microalgae by organic solvent and supercritical $\mathrm{CO}_{2}$ Bioresour. Technol. 102 10151-53.
2. Xia S, Zhao X, Frigo-Vaz B, Zheng W, Kim J and Wang P 2015 Cascade enzymatic reactions for efficient carbon sequestration Bioresour. Technol. 182 368-72

3. Xia S, Frigo-Vaz B, Zhao X, Kim J and Wang P 2014 Biocatalytic carbon capture via reversible reaction cycle catalyzed by isocitrate dehydrogenase Biochem. Biophys. Res. Commun. 452 147-50

4. Prescott J and Rabinowitz L 1968 The enzymatic carboxylation of propionyl coenzyme A. Studies involving deuterated and tritiated substrates J. Biol. Chem. 243 1551-57

5. Gameiro A, Laviolette A, Kelleher K, Iliopoulos O and Stephanopoulos G 2013 Cofactor balance by nicotinamide nucleotide transhydrogenase (NNT) coordinates reductive carboxylation and glucose catabolism in the tricarboxylic acid (TCA) cycle. $J$. Biol. Chem. 288 12967-77

6. Maren H 1967 Carbonic anhydrase: chemistry, physiology, and inhibition Physiol. Rev. 47 595-781

7. Dalziel K 1975 1. Kinetics and Mechanism of Nicotinamide-Nucleotid-Linked Dehydrogenases. The enzymes 11 1-60

8. Yang W, Cicek N and Ilg J 2006 State-of-the-art of membrane bioreactors: Worldwide research and commercial applications in North America J. Memb. Sci. 270 201-11

9. Xia S, Wang P and Kim J 2015 pH sensitivity of carbon dioxide conversion catalyzed by isocitrate dehydrogenase Greenh. Gases. 5 102-07

10. Kobayashi T and Moo-Young M 1971 Backmixing and mass transfer in the design of immobilized enzyme reactors Biotechnol. Bioeng.13 893-910.

11. Hofstee $\mathbf{J} 1952$ On the evaluation of the constants $\mathrm{V}_{\mathrm{m}}$ and $\mathrm{K}_{\mathrm{m}}$ in enzyme reactions Science 116 329-31. 